\title{
COVID-19 tingitud folkloristlikud reaktsioonid Valgevenes
}

\author{
Tatsiana Valodzina \\ Valgevene Teaduste Akadeemia \\ Valgevene kultuuri, keele ja kirjanduse uurimise keskuse \\ slaavi rahvaste folkloristika ja kultuuri osakonna juhataja \\ tanja_volodina@tut.by \\ Tatsiana Marmysh \\ Valgevene Teaduste Akadeemia \\ Valgevene kultuuri, keele ja kirjanduse uurimise keskuse \\ slaavi rahvaste folkloristika ja kultuuri osakonna teadur \\ ta-m@tut.by
}

\begin{abstract}
Teesid: Artikkel uurib COVID-19 pandeemiast tingitud kriisisituatsioonile järgnenud reaktsioonide arhailisi skeeme Valgevenes. Üksikasjalikult käsitletakse iidse rituaali aktiviseerumist ühepäevaliniku loomise ja pühas kohas ohverdamise näitel. Kirjeldades pandeemia mõju mõnele kombele, jõuavad autorid järeldusele, et selle rakendamine kriisiajal oli kogukonnale eriti oluline. Artiklist ilmneb, et ka uutes folkloorivormides peituv huumor on üks tee kriisiolukordadest jagu saamiseks.
\end{abstract}

Märksõnad: arhailisus, kriisisituatsioon, naer, pandeemia, rituaal

\section{Sissejuhatus}

Ülemaailmsed epideemiad (pandeemiad) ja paikse levikuga epideemiad on inimkonda saatnud kogu selle eksistentsi vältel. Need vahelduvad hoolimata meditsiini arengust, tehnoloogilistest läbimurretest, inimeste eluviisi muutustest ja selle sotsiaalkultuurilisest alusest. Tsivilisatsiooniline areng ei võimalda täiel määral vältida nakkuste ohtu ja sellest tingitud kriisiolukorda, samuti ei võimalda see üle saada atavistlikust hirmust igasuguse "katku" ees (Tuchman 1993: 99-128), mis kaasneb aastail 1347-1352 Euroopas musta katku ajal juurdunud kollektiivse traumaga (Vovelle 2004: 107). See hirm on sügavalt juurdunud, stereotüüpne, ei muutu ajas ega ruumis.

Hirmu ületamise mudelid kultuuris hõlmavad hirmule vastupanu osutamist ja selle muutmist. Kriisiolukorrast ülesaamiseks on mitmesuguseid mehhanisme: 
ohu eitamine, kriisiolukorra passiivne aktsepteerimine, ennetusmeetmete kasutuselevõtt ohuolukorra vältimiseks ja elutingimuste põhjalik muutus korduvate kataklüsmide mõjul (Burton \& Kates 1993: 121-124).

Epidemioloogilise ohu korral on tuvastatud mitmeid stereotüüpseid sotsiaalse reaktsiooni mustreid, mis lähtuvad Euroopas katku ajal käitumise mudelitest. Need sisaldavad olemasolevate käitumisnormide hülgamist, sealhulgas tavatut julmust, omaenda elu päästmist iga hinna eest, positiivsete tunnete ja empaatia kadumist, labasust ja joomarlust, äärmuslikku agressiooni, ka enesevastast agressiooni ja ärevuse mahasurumist. Ärevuse vastu aitavad ühislaulmine, enese ja ennast ümbritsevate rahustamine, samuti ärevusetekitajast distantseerumine huumori abil (Kępiński 1977: 146-147). Ärevusest jagusaamise individuaalsed viisid ei erine oluliselt rühma rahustamise sotsiaalsetest mehhanismidest, välja arvatud see, et sageli jõuavad need emotsionaalsesse tippu - maksimaalne agressioon, äärmuslik desintegratsioon või ülemäärane lõimumine. Nende hulka kuulub ka olukorrast distantseerumine huumorimeele abil ja transtsendentaalne suhtumine oma ellu, mis lakkab olemast väärtushierarhia kõige kõrgem väärtus, mis omakorda vähendab surmahirmu (Kępiński 1977: 147).

Kaitsemehhanismina võib toimida ka isiklikust vabadusest loobumine teiste kasuks, mis põhineb sotsiaalsetel suhetel ning kehastab kogukonnale olulisi ja seda siduvaid ideid (Kutnik 2017: 109). Ärevatest emotsioonidest jagusaamine muudab rituaalseks inimese eneseleidmise strateegiad ohuolukorras, mis on iseloomulik traditsioonilisele kultuurile. Rahvakultuuris on kriisiületamise mehhanismidel sageli rituaalmaagiline iseloom.

Erandiks ei olnud ka COVID-19 tingitud olukord. 2020. aasta märtsis, mil pandeemia tase muutus Valgevenemaal tuntavaks ja vaatamata valitsuse strateegiale eitada koroonaviiruse ulatust ja ohtlikkust ${ }^{1}$, hakkasid levima ärevus, mure ja isegi hirm, muutusid märgatavalt aktiivsemaks inimeste reaktsioonid, mis põhinesid täiesti arhailistel ohust jagusaamise mudelitel.

Käesolevas artiklis anname ülevaate pandeemiale reageerimise rahvalikest vormidest Valgevenes selle esimese laine ajal (2020. aasta kesksuveni).

Artikkel põhineb pandeemiateemaliste intervjuutekstide ning interneti-kasutajate visuaalsete testireaktsioonide (meemid, luuletused, kõnekäänud) sisu kvalitatiivsel analüüsil. Kasutati tekstiandmetel põhinevat rekonstrueerimise ja sündmuste analüüsi meetodit, samuti vaatlust. 


\section{Pandeemia kiiretes folkloorsetes reaktsioonides}

Koroonaviiruse pandeemia on nii maailmas kui ka Valgevenes toonud kaasa rahvaloomingu kõikvõimalike žanrite võimsa plahvatuse. Virtuaalse suhtluse ülekaal ja interneti laialdane kasutamine on loonud mitmesuguste tekstide, nii suuliste kui ka pildiliste (graafiliste) tekstide kiireks levitamiseks. Valgevenes levitati neid sellistes sotsiaalvõrgustikes nagu Facebook, Twitter, Telegram, Viber, VKontakte. Suur osa postitustest põhineb valgevenelaste traditsioonilisel maailmavaatel ja on vormistatud pärimusepõhiselt (ümbersõnastused, tšastuškad, anekdoodid, antikõnekäänud, vanasõnad jne).

Там, за мяжой - карантын, пандэлія.

Тут - калбайнёр сьпіртал горла пралые.

Каранавірус - дзіцячыя казкі.

Нас уратуюць хакейныя маскі

[Seal piiri taga karantiin, pandeemia.

Siin kombainer peseb kõri piiritusega.

Koroonaviirus see on lastejutt.

Meid päästavad hokimaskid.]

(Viirusehirmutis, autor Andrej Khadanovich, 2020). ${ }^{2}$

Mõtestades COVID-19 ja enda suhtumist sellesse folkloorivormide vahendusel, kasutavad vastukajade loojad olemasolevaid teadmisi ja stereotüüpe, kujundeid, mis on suures osas salvestunud mällu varasemate epideemiate ja katastroofide kogemusest. Inimkonna kultuuripagas sisaldab emotsionaalseid õppetunde, rahvameditsiini ja kunstivorme, et luua teadmisi epideemiate kohta. See üsna stabiilne ja samas detailides muutuv võrgustik aitab aktualiseerida rahvaloome vahendusel juba olemasolevat ohtude üleelamise kogemust 21. sajandil. Raskes olukorras, kui ühiskond kohtub uue ohuga, on pöördumine tuttavate ideede poole positiivne, selle eesmärk on luua tingimused, milles on kergem üle elada vaimne trauma.

Tohutult on suurenenud huumori roll, kuivõrd just huumor on normaalne reaktsioon üldise ohu korral. Naljad ja naer välisohuga silmitsi seistes - see on kompensatsioonimehhanism, mis aitab üle saada hirmust ja teadmatusest, ühine naermine ühe ja sama asja üle aitab kokku hoida ja omandada uusi käitumisreegleid. Seetõttu on humoorikas folkloor COVID-19 kohta mitte üksnes psühhoteraapiline, vaid aitab teadvustada ka kuulumist ühiskonda. Praeguseks kogutud materjalid näitavad, et huumor ei käsitle isikliku haigestumise võimalust, vaid teatud hügieenivõtteid (homme kästakse iga tund pesta mitte üksnes käsi, vaid ka jalgu), karantiiniolukorda (28. veebruar - püha karantiinipäev. Üksteisele võib kinkida karantinkasid $),{ }^{3}$ ametivõimude omapärane suhtumine 
pandeemiasse (Valgevene piiri ületamisel kaotab koroonaviirus oma patoloogilised omadused ja muutub tavaliseks ülemiste hingamisteede viirusnakkuseks), samuti uue reaalsuse tingimused (Uitavad inimesed maskides, / erksad näivad, / ei oskagi kohe arvata, / kellel on Covid). ${ }^{4}$ Sisuliselt toodetakse tekste, mis reageerivad mitte epideemiale endale, vaid kaitsemeetoditele, mida alles välja töötatakse ning mõtestatakse neid rahvakultuuri kaudu (vastlapäeval tuleb põletada koroonaviiruse kuju). ${ }^{5}$

Што рабіць на караниіне?

Піць гарэлку дь мариіні!

Ну, а лепей самагонку!

Толькі хукайце ў старонку.

Рукі хуиенька пальиице,

Столік быстрынька накрыйще,

Каубасу, грудзінку, сала...

Паглядзіце, каб не мала.

Сялядзец дь карташьну,

Курку грыль, салат, масліну.

Можна піциу заказаць,

Дь халера, доуга ждаць.

Абылзелся тыли што е!

Ну! Ужо можа хто налье?

Не, не, не! Мьь не бухаел!

Толькі вірус выганяел.

Хай варочае ў Kimaŭ

Нy! Па другой налівай!

Каб нас вірус абыџоо̆!

За сталол нас не знайшоу!

Нал хавациа не з рукі

Унас бабы, мужыкі...

Як нап'елся салагону,

Знілем вірусу карону.

Наліваел! Будзь здарой!

Ну, а трэиия ж за любоў!

Вершык усіл Вали разашлю!

Бо я вас усіх люблю!

Вьи ўсе зараз пасмяецесь!

И здоровья наберетесь!

Набярыиясь пазітыву,

Наш народ - то проста дзіва! 
У свеце ён такі адзін.

Чхалі мь на караниін!!!

[Mida teha karantiinis?

Viina juua ja martiinit!

Parem veel on samakas!

Ainult hingake kõrvale.

Ruttu peske käed,

Kiirelt katke lauake,

Vorst, rinnatükk, pekk...

Vaadake, et poleks vähe.

Heeringat ja kartulit,

Grillkana, salat, oliiviõli.

Võib ka pitsa tellida,

Sindrinahk, kui kaua ootad.

Ajame läbi sellega, mis on!

Noh! Juba võib, kes kallab?

Ei, ei, ei! Me ei joo!

Ainult viirust peletame.

Las läheb tagasi Hiinasse

Noh! Vala teine!

Et meist viirus mööda läheks,

Laua taga meid ei leiaks!

Peita meil ei ole mõtet,

Meil on eided, mehed ka...

Kui me joome samagonni,

Viiruselt võtame krooni,

Kallame! Terviseks!

Aga kolmas armastuseks!

Luuletuse saadan kõigile!

Sest teid kõiki armastan!

Praegu kõik te naerda saate!

Ja tervist endal kogute

Kogute ka positiivsust!

Meie rahvas - lihtsalt ime!

Ainus selline maailmas.

Karantiini peale aevastame!!!

Ilmselgelt aitab humoorikas folkloor kui kiire reageerimisvorm kohaneda uute normidega ja üle elada vanade normide murenemise. 


\section{Ohu üleelamise kollektiivsed rituaalid}

Kahtlemata on valgevenelastel tulnud epideemiatega rinda pista ka enne 2020. aastat. Kuid sellistel aegadel kasutatud rahvalikest rituaalmaagilistest vahenditest pole kuigi palju andmeid talletatud. On tähelepanuväärne, et üldjuhul on hõlmatud olnud kogu kollektiiv, need on tegevused, milles nii või teisiti osaleb kogu küla. Ja tulemust oodatakse kõigile. Igaüks võib iseenda abistamiseks ette võtta suitsutamise teravalt lõhnavate vahenditega - koirohu ja kikkaputkega. Kuid lõpliku tulemuse annavad vaid tegevused, mida sooritavad kõik koos. Tegevuse kollektiivsuse välisohu korral määrab ühest küljest ühiskonna rühmaidentiteet, usaldus põlvkondade jooksul kogunenud ühise kogemuse vastu rituaalis aktualiseeritud kollektiivse kultuurimälu kaudu (Assman 2004: 20), aga teisest küljest formeerib seda identiteeti ühiseks eesmärgiks püüd ennast kindlustada.

\section{Ühepäevalinik kriisiolukordades}

Kõige sagedasem, jälgitavam ja mõistetavam rahvalik vahend epideemia ennetamiseks oli küla sulgemine maagilisse ringi. Tegevuses on säilinud ebatavaliselt arhailised ja olulised detailid, mis on seotud nii osalejate kui ka ajaga, rekvisiitidega jne. Õigupoolest oli tegevus nii esemeline - küla ümber künti vagu, tõmmati joon ahjuhargi või -roobiga või veeti selle ümber tavaline niit kui ka sümboolne: ümber küla kanti päevalinikut, korraldati ristikäik.

Üleskündmise fikseerimisest eraldab meid rohkem kui sajand, seevastu tavandiliniku valmistamise viimast tõusu võis täheldada Teise maailmasõja ajal, kui rituaali sooritati, et sakslased ei paneks küla põlema (каб не спалілі немиьь вёску), et inimesed tuleks sõjast tagasi (каб вярнуліся з вайнь). Tseremoonia sisu seisneb selles, et päevavalges, harvemini ka öö või ööpäeva jooksul, tuleb läbi teha kõik lõuendi loomise etapid alates lina kraasimisest kuni valmistooteni. Siit ka nimetus - päevalinik (абыцдённік, абыцденнае палатно).

"Ці чулі вы такі абыдзённік?" “Яго ткалі як вайна была. I тут у Малеве. Ставілі крэст на крыжавых дарогах $і$ ноч'ю ткалі такія хвартушкі і прывязвалі да гэтых крастоў. Мужчыны ноччу крэст ставілі. А жанчыны яго уббіралі, абвязвалі такімі хвартушкалі, палаценцамі"

["Kas olete kuulnud päevalinikust?" - "Seda kooti, kui oli sõda. Siin Malevas ka. Ristteedele pandi riste ja kooti öösel sellised põlled ja seoti nende ristide külge. Mehed panid öösel risti. Aga naised kaunistasid seda, sidusid 
ümber sellised põlled, linikud"] (T. Valodzina üleskirjutus 2014. a Njasviži rajooni Maleva külas, informant L. M. Barbaryč, snd 1931 (FATV).)

Было такоя, што за адну ноч ткалі такую налітку. Да, да, у вайну. Вот, мае дзеткі, як: сабіраліся лы у адну хату, лён мялі у мялку, вынтрапалі, пакрасілі, спралі і за ноч саткалі. I тады да уусхода сониа абняслі кругол дзярэўні і заняслі у иэркву ў Буй аддалі. У вайну, кааб вайна кончылася. Усе сабіраліся, і жанчыны, $і$ дзеўкі...

[Oli nii, et ühe ööga kooti selline linik. Jah, jah, sõja ajal. Vaat, mu lapsed, kuidas: läksime ühte onni, ropsisime lina, kraasisime, värvisime, ketrasime ja kudusime ühe ööga valmis. Ja enne päevatõusu kandsime ümber küla ja viisime Bui kirikusse. Sõja ajal, et sõda lõppeks. Kõik kogunesid, naised ja tüdrukud...] (T. Valodzina ja V. Lobatši üleskirjutus 2008. a Sjanno rajooni Niamojta külas, informant E. M. Halavač, snd 1929 (FATV).)

Kui fašistid süütasid naaberküla, kudusid Krupki rajooni Dzianisavičy küla naised päevaliniku, viisid selle risti juurde, aga spetsiaalselt kedratud lõnga sidusid ümber küla; rituaaliks kulus umbes viis kilomeetrit lõnga. Huvitaval kombel on rituaal omandanud erijooni. Näiteks Puchavicki rajooni Kliaciščana külas riputas Jeva Niemahaj lubadustega päevatooted kõigile ümberkaudsetele teeäärsetele ristidele, ja kõik ta kuus poega tulid sõjast koju. Teine selle küla naine keeldus koos temaga rituaali läbi viimast, tema omaksed rindelt ei naasnud (Labačeǔskaja 2011: 876).

Päevalinik on imeline käsitöö: kangatükk, mis on omandanud erakordselt sügava sümboolse tähenduse ja mõjuvõimu. Looduselemendi ümberkehastumise fakt, tooraine teekond valmis kultuuritooteks veenis inimest korra taastumise vajaduses ja tagas maagilise kaitse kõigi kaose ilmingute vastu. Ikaldusest sõjani. Liniku imeline sünd kõigi elanike kohustusliku osalemisega kujutas endast erakordset tahtejõu kontsentreerimist häda (epideemia) võitmiseks.

Мы пралі. I я прала. Рушнік абыкнавенны. За дзень нада напрасиі, $i$ аснаваць, $і$ выткаць, $і$ павесіць. I бащюшку нада было прывесці. Хрэст мужчьны дзелалі і ставілі на перакростку. А жэншчыны ткалі. Ужо после вайны. Мне ложа было 10 гадоў. Мы $і$ бегалі дзяўчынкі кругол дзярэўні. А такі тады дож лінуў. А иі эта ад таго... А чаго бегалі кругол дзярэўні? Нада было той салай ніткай, якую пралі у гэты дзень, абходзілі тры разы дзярэўню. Нас, дзяцей, адправілі. Нада каб дзевачкі, каторыя ня ілелі нічога.

[Me kudusime. Mina kudusin ka. Päevalinikut. Päevaga on vaja kedrata, kangas luua, kududa ja üles riputada. Ja isake oli vaja kohale tuua. 
Mehed tegid risti ja seadsid selle ristteele üles. Aga naised kudusid. Juba pärast sõda. Ma olin võib-olla 10aastane. Me tüdrukud jooksimegi ümber küla. Aga kuidas tookord vihma kallas. Aga kas siis sellest... Aga miks jooksti ümber küla? Sellesama lõngaga, millest sel päeval kooti, oli vaja küla kolm korda ümber vedada. Meid, lapsi saadeti. Oli vaja tüdrukuid, kellel ei oleks midagi.]

(T. Valodzina üleskirjutus Berazino rajooni Čyžacha külas 2010. a, informant A. I. Karsuk, snd 1929 (FATV).)

Linikut, kangast kanti ümber küla selleks, et eraldada küla korrastatud ruum seda ümbritsevast ähvardavast kaosest, ohverdati erilises pühas paigas. Seal, kus sind võisid kuulda taevas ja kõrgemad jõud. Kirjelduste kohaselt oli see eelkõige kas pühakoda või püha allikas. Kirik on palve esitamiseks kõige mõistetavam koht, mis tagab palve kuulmise ja täitmise. Sugugi harvem polnud komme siduda päevalinikuid-käterätte looduslike ristide külge, et see oma kohaloleku märgina kaitseks küla, muutuks ületamatuks takistuseks hädade tungimisele inimeste elutsüklitesse. Selline rist olid juba iseenesest kaitse välisohtude eest, aga ristile seotud rätik suurendas kaitseefekti veelgi.

Päevaliniku maagilised omadused arvatakse tulenevat tema uudsusest, absoluutsest puhtusest, millega kokkupuutumisel negatiivne jõud hävineb. Lõuendi puutumatus seostus maailma uuenemise ja algse puhtuse juurde naasmise ideega. Oluline on kogu protsessi terviklikkus ja toimumine lühikese aja jooksul, mis annab tootele sakraalsuse ja erilise maagilise jõu. Teadlased on üsna täielikult kirjeldanud selliste toodete kaasamise mehhanisme kriisiolukorrast väljatulemiseks. Nii jõuab Albert Baiburin järeldusele: “igapäevane ese, ideaalis uus ja puhas, mis ei ole jõudnud tootmisprotsessis "vananeda", sai uuenenud elu idee kehastuseks sellisena, nagu see oli alguses, enne kriisiolukorra tekkimist... Rituaali sügavam semantika seisneb vana (nõrga, kulunu, oma jõu kaotanu) regulaarses taassünnis, muutumises uueks, täis võimalikku jõudu ja võimalusi kollektiivi õitsvaks eksistentsiks" (Baiburin 1993: 150).

Aleksandr Strahhov seostas rituaali nn operatiivtekstidega, mis tavaliselt tähendavad ülevaadet kultuurtaimede "elust ja kannatustest" alates nende kasvatamise algstaadiumist kuni söömisvalmis toodeteni. "Igapäevane" tootmine ei ole jutt, vaid suulise "operatiivteksti" ritualiseeritud subjektitõhus kehastus, mis on kokku surutud ajas ühte päeva või öösse, harvemini ööpäeva. Kaitsemaagias kasutatakse mõlemat teksti, nii tegevuslikku kui ka verbaalset kultuuri ja korra loomiseks, mis vastanduvad loodusele ja kaosele ning nende tekitajatele - stiihiatele, haigustele, kurjale vaimule (Strahhov 2018: 8). 
Valgevene territooriumi puhul on iseloomulik ka asjaolu, et tavarituaali võis võimendada ka igaaastase tõotuspraktikaga. Näiteks Vitsebski oblasti Hłybokaje rajooni Papšyčy külas sooritavad külaelanikud roheliste talsipühade (Зялёнья свёнткі, püha vaimu sõnum apostlitele) puhul rituaali lihtsustatud variandi, milles on säilinud sõlmpunktid - kõigi naiste osalemine kanga valmistamisel (praegu valge kanga ostmine), asunduse ümber käimine, ohverdamine pühakojas (foto 1). Traditsiooni taaselustamise ajendiks oli epideemia lõppemine pärast päevaliniku rituaali sooritamist. M. F. Kušniareviči (snd 1941) sõnade kohaselt:

Нашто носяиь, гэтак нашыя бацькі казалі. Ну, гэта яшчэ не знаю, да вайны, иі гэта... Страшная хвароба была - халера. Усіх людзей сплош радал. Ну, што рабіць? Ужо тут блізка і гэта... Сабралася вёска. За ноч выткалі палатно. Ну, якое тал што ў каго было зняслі тал і выткалі. I што рабіць? Лл вёскі была дарога вакруг даўней, круга вёскі хадзілі. Ну сабраліся ўсе і пашлі гэтай [дарогай]. I ружанеи $і$ мадлітвы $і$ пашлі круга вёскі ужо прасіщь Бога, кааб абараніў ад гэтай халеры. I праз нескалька, ну, і иішына. Ніякія ужо [не ўміралі]. У Зялезьках уліралі, тал радал гэтыля. Уліралі, уліралі. Тады некалу тут са старых саснілася, гэта, хвароба. Кажыць: “Чаго ты прычапілася?!” (Ну, дзе ууліралі) Ідзі у Папшычыь! (Што тут ніхто не ўліраіць). Кажыць: "Не пайду. Тали рыжы сабака круга вёскі лётаіиь”. Ну і ніхто не палиер

[Sellepärast kantakse, et meie vanemad ütlesid nii. Aga seda veel ei tea, kas enne sõda või see... Hirmus haigus oli - koolera. Kõiki inimesi alailma. No mida teha? Juba siin lähedal see... Küla tuli kokku. Öö jooksul kooti kangas. No mis seal siis, kellel mis oli, toodi kokku, loodi üles ja kooti. Ja mida teha? Küla lähedal oli tee selle ümber varem, ümber küla käidi. No tulid kõik kokku ja läksid mööda seda [teed]. Ja roosikrants ja palved ja mindi ümber küla juba Jumalat paluma, et kaitseks selle koolera eest. Ja mõne aja pärast, noh, ja vaikus. Juba mitte keegi [ei surnud]. Zialieźkis surid, seal kõrval need. Surid, surid. Siis tuli kellelegi vanadest unes see haigus. Ütleb: "Miks sa külge tuled?!" (No seal, kus surid.) Mine Papšyčysse! (Sest siin ei sure keegi.) Ütleb: "Ei lähe. Seal lendab punane koer ümber küla.” Ja keegi ei surnudki] (Filipčyk 2014: 379).

Kõik vaadeldud rituaalid sooritati või väheste kinnituste kohaselt sooritatakse jätkuvalt külades, s.t pärimuskultuuri loomulikus keskkonnas. Seal on nad mõistetavad, toetuvad suurema osa elanikkonna üldistele taustateadmistele ja kollektiiv toetab neid tingimusteta. 


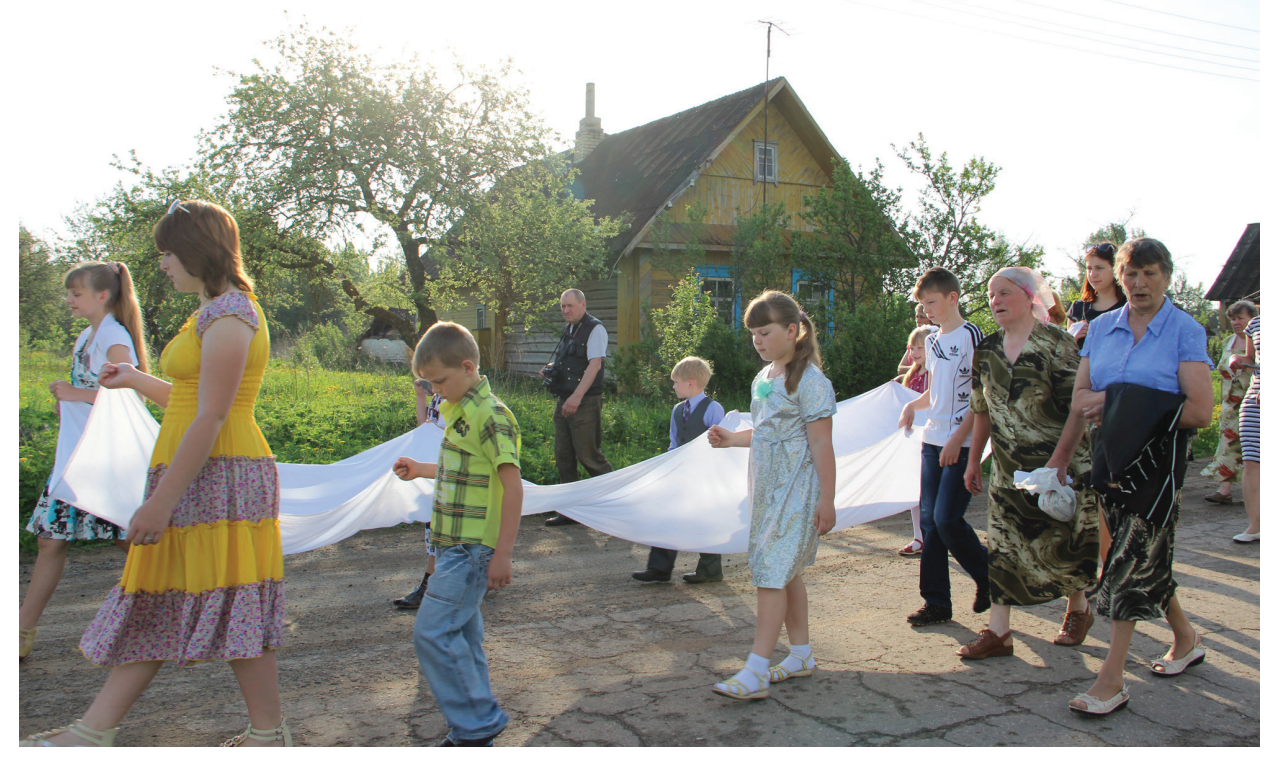

Foto 1. Papšyčy lina. Tatsiana Marmyshi foto 2013.

\section{Ühepäevarätik pandeemia vastu võitlemise vormina}

Käesolevaga tahaks märkida üsna huvitavat ja tavatut rituaalset käitumist mitte enam külaelanikel, vaid linlastel. 28. märtsil viidi Minskis võimalikult täpse tavandijärgimisega läbi ühepäevariitus (foto 2). Selle initsiaatorid ja osalised olid peamiselt üliõpilaste etnograafiaühingu liikmed, kes toetavad valgevenelaste pärimuskultuuri, kusjuures kaugeltki kõik ei ole enam tudengieas. Sotsiaalmeedias edastatud üleskutsele reageerisid ka rahvaliku käsitöö huvilised, käesoleval juhul kangakudujad. Teave eelseisvast sündmusest esitati järgnevalt:

... Зауттра мы будзел ткаць такі рушнік. Збяруциа ткаллі, праллі і проста неабыякавыя людзі, выканаюиь увесь цыкл ткання, пасля рушнік будзе ахвяраваны на святое месца. Што вы можаце зрабіць салі? Калі вы улмееце ткаць і жывеце не у Менску -збірайце талаку і тчыце у сябе. Гэта можа быць не толькі рушнік, але і пояс. Будзем ратаваць сусвет разал! 


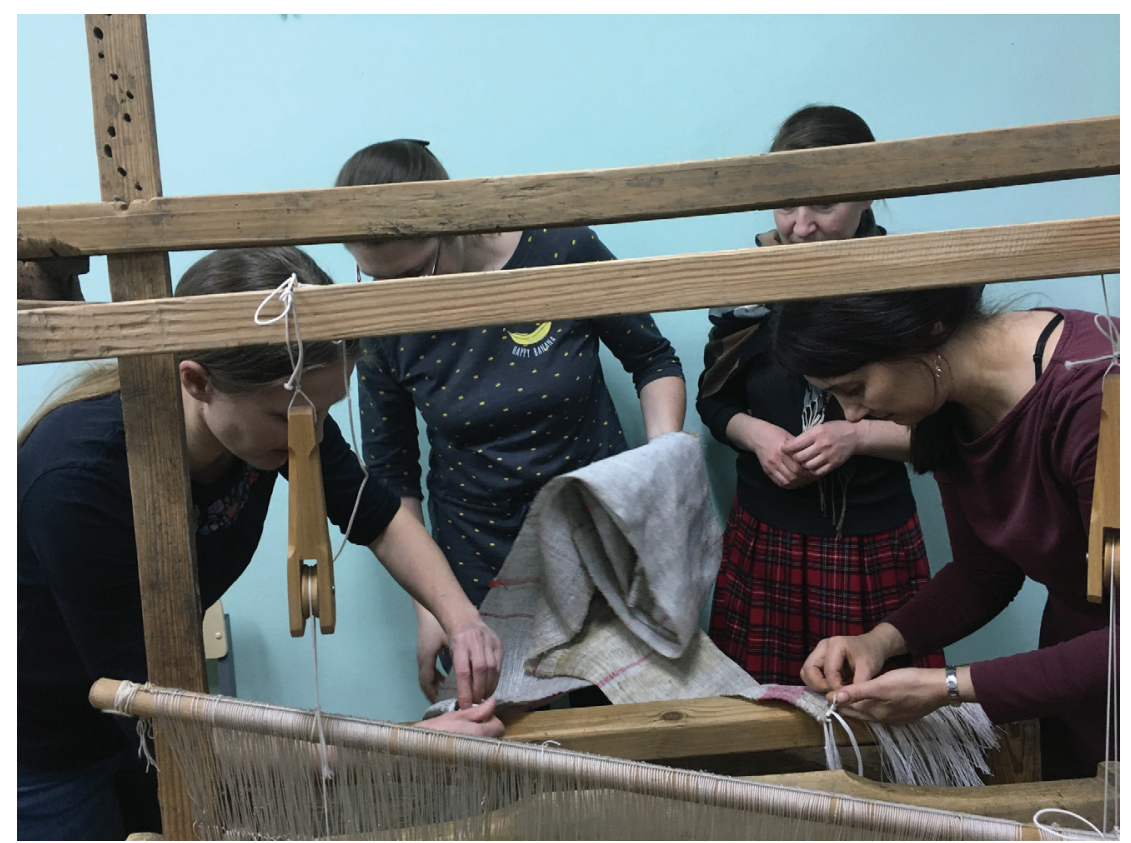

Foto 2. Liniku valmistamine. Sviatlana Klepikava foto 2020.

[Homme me hakkame kuduma sellist linikut. Kokku tulevad kangakudujad, ketrajad ja inimesed, kellel pole ükskõik, teeme läbi kogu kangakudumise tsükli, pärast saab linik pühas kohas ohverdatud. Mida te saate ise teha? Kui te oskate kangast kududa ega ela Minskis - tulge kokku ja kuduge enda juures. See ei pea olema üksnes linik, võib olla ka vöö. Päästame koos maailma!]

Igas ühiskonnas reageerisid ja reageerivad eri sotsiaalsed kihid ohule erinevalt. Erinevused sõltuvad märkimisväärselt inimese osalemisest kõikvõimalikes ühendustes alates usuühendustest kuni professionaalsete kooslusteni, samuti tema isiklikest teadmistest ja emotsioonidest. Päevaliniku valmistamise kogemust Minskis ei saa pidada tüüpiliseks, kuid sellise kombe aktualiseerumine on tähelepanuväärne mitmel põhjusel.

Ühel käesoleva artikli autoritest õnnestus selles aktsioonis osaleda, mis annab võimaluse kinnitada osalejate üksmeelt ja pingelist keskendumist. Me oleme korduvalt välitöödel üles tähendanud vanema põlvkonna jutustusi ja neile kaasa elanud. Sel päeval püüti seostada rituaali kulgu ja üksikasju tuntud mudeliga. Kuid sakraalses tegevuses osaleja roll tõrjus peaaegu täiesti kõrvale 
folkloristi pilgu. Sugugi kõik tegevuses osalevad naised ei osanud kedrata ega kududa, kuid said hakkama mingite lihtsamate operatsioonidega, ning iga osaleja võimetest ja oskustest kasutati ära maksimum. Emotsionaalne meelestatus oli ühtne. Tahaks arvata, et see oli samasugune nagu meie eelkäijatel.

Tundes ennast ühtse terviku osana usaldavad rituaalis osalejad üksteist, mõtlevad sünkroonis ja tegutsevad koordineeritult. Ühist ajaveetmist iseloomustasid kooskõla ja harmoonia, mis olid hädavajalikud rituaali kõigis etappides, ning eriti päevalina puhul oli oluline kinnipidamine ajalisest piirangust.

Valmis linikut kanti ümber Minski ja päikeseloojangul seoti see pidulikult ümber kivi, mis kannab nime Taat. Varem asus kivi Minski kesklinnas paganausu templi juures, see teisaldati ehitustööde tõttu Kivimuuseumi eestvõttel äärelinna. Lina seoti ümber kivi, selle ümber veeti ka samal päeval kedratud lõng (foto 3). Päevalina kanga lahtilõigatud lõimed põletati. Seejuures lauldi rahvalikke laule, kivile toodi tagasihoidlik kost.

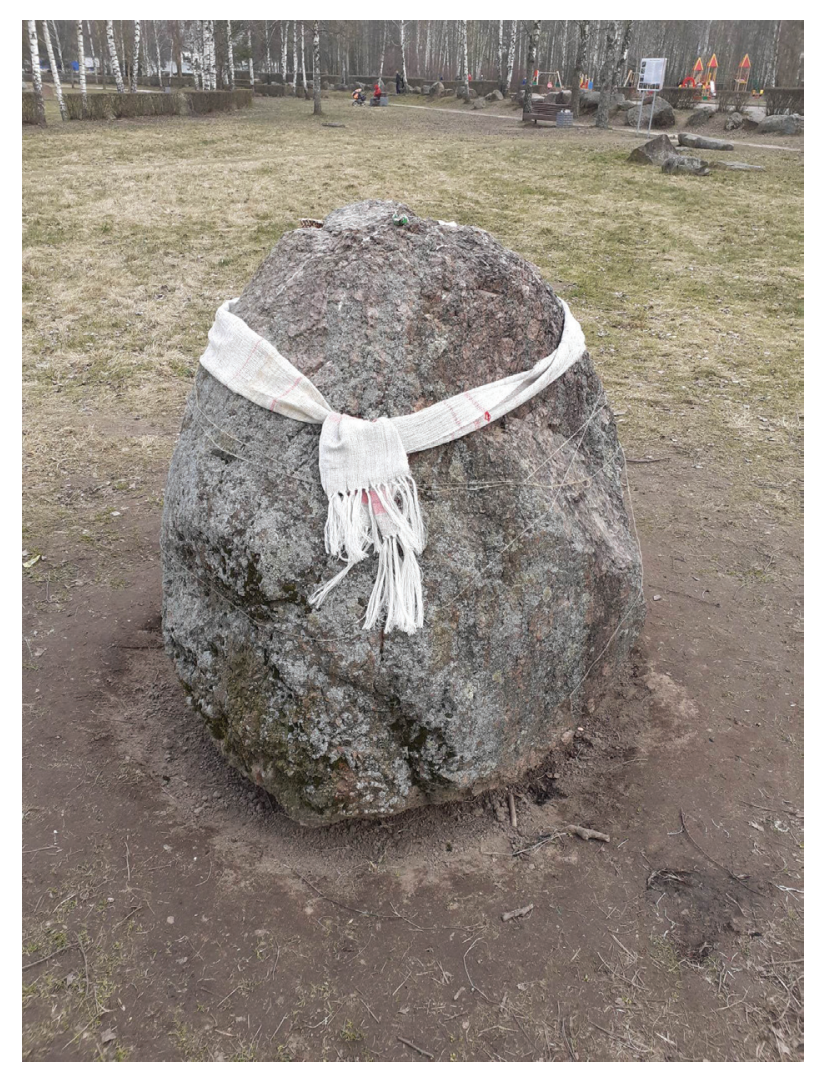

Foto 3. Kivi Taat selle ümber seotud linaga.

Tatsiana Valodzina foto 2020. 
Facebooki postitati ka omamoodi aruanne ettevõtmisest:

2020.03.28

Päevalina...

360 lõimelõnga...

12 inimest

12 tundi ketramist, kangaloomist ja kudumist...

kolm meetrit ja peale...

ring ümber Minski...

kivi Taat...

laulud...

Kuivõrd internet oli selle rituaali puhul esmane suhtlusplatvorm, tahaksime juhtida tähelepanu Facebooki ja VKontakte postituste all ilmunud kommentaaride üldisele positiivsusele. Kommentaarides on tänusõnu rituaalis osalejatele, heakskiite valitud pühakohale, vaimustust päevaliniku ilust ja isegi ülestunnistus, et rituaal andis inspiratsiooni kangakudumiseks. Kahtlustuse puhul, et "kurjad käed" võivad kivi külge seotud liniku rikkuda, ilmutas üks rituaalis osalenutest huvitaval kombel selles situatsioonis täiesti mütoloogilist mõtlemist, kommenteerides: “...зганьбяць иі не, яно не прыниьпова, справа зроблена..." [kas rüvetavad või mitte, pole oluline, tegu on tehtud...] (kommentaar sotsiaalvõrgustikus VKontakte leheküljel DAINAVA.Folk, ritual, https:// vk.com/dainavafolk - vaadatud 01.10.2020).

Analüüsides ühepäevalinade valmistamise puhangut sõja ajal kirjutab Oĺga Lobachevskaya: "Sõjaaegne pöördumine kollektiivse loomuga päevarituaali poole tähendas püüet saavutada korrastatust, regulatsioone ja psühhoteraapilisi eesmärke. Rituaal leevendas osalejate pingeid ning aitas kaasa solidaarsuse teadvustamisele ja kollektiivsete sidemete tugevdamisele, selle abil saavutati empaatia ja ühtsustunne, mis aitas leevendada kaotuste raskust ning tugevdada lootust vabaneda ebaõnnest ja päästa lähedasi. Selliselt rahuldas rituaal nii indiviidi kui ka kogu sootsiumi vajadusi" (Lobachevskaya 2010: 44). Peaaegu kõik rituaali loetletud eesmärgid olid olemas ka 2020. aastal. Muidugi on tänapäeva linnainimesel, eriti kui ta on noor, raske täielikult kõrvale lükata mõnda lavastuslikku või isegi mängulist varjundit. Kuid traditsiooni raames leidsid kehastuse psühholoogiline ja emotsionaalne komponent. 


\section{Elavad kombetäitmised kriisiolukorras}

COVID-19 pandeemia halvas elava traditsiooni järgimist. Näiteks lükati määramata ajaks edasi UNESCO inimkonna vaimse pärandi nimekirja kantud Budsłaŭ pidustused. Siiski viidi ajalisi ja ruumilisi piiranguid jälgides läbi mõned iga-aastased kombetalitused. Nende seas Juraŭski karahod Žõtkavitšõ rajooni Pahosti külas, näkineiu ärasaatmise rituaal ${ }^{6}$ Hoiniki rajooni Vialiki Bori külas (foto 4), Kusta juhatamise riitus Luninetsi rajooni Lobča külas.

Keerulise epidemioloogilise olukorra tõttu muudeti tseremooniate tavapärast korda - traditsioonilist struktuuri rikkumata lühendati nende kestust: varem käis Kusta Lobčas läbi kogu küla, 2020. aasta juunis vaid osa sellest. Tavaliselt tulevad tseremooniapäevadel küladesse ajakirjanikud ja huvilised riigi teistest piirkondadest, sedapuhku võtsid ringkäikudest osa üksnes kohalikud elanikud.

Selliselt formaati kärpides taastas pandeemia kohalike traditsioonide algsed tingimused, mis tähendas rituaalide läbiviimist vaid kitsas kogukonnaringis, see võimaldas teatud määral välistada üleliigse ning säilitada vaid selle, mis objektiivselt on arhailise kombestiku juures kohalikele elanikele oluline. Püüdu jätkata tavapäraste kombetalituste täitmist ka ohuolukorras, mida COVID-19 kaasa tõi, ilmneb kohalikele pärimusekandjatele ilmselgelt oluliste elementidena ja kombetäitmistesse lisanduvad ka uued mõtted, sealhulgas vastuseis ähvardavale ohule.

Pandeemia tingimustes kombetalituste läbiviijatel võimaldab see moodus võtta maha stressi ja jagada oma muret inimestega, kellel on sarnased huvid. Traditsioon on nende elu üks püsielement, mille poole pöördumine aitab kriisiolukorras ühiskonda stabiliseerida. Selliselt ilmnes pandeemia ajal inimeste vajadus kultuuri ja traditsioonide järele.

Traditsioonilist kultuuri kasutav loomemajandus on pandeemia tõttu languses - festivale ja kultuuriüritusi ei korraldata, mistõttu võib langeda ühiskonnas traditsiooniliste teadmiste valdajate enesehinnang. Valgevenes jäeti 2020. aastal ära märgilised folkloorisündmused (rahvaloomingufestival "Bierahinia", rahvuskultuurifestival Grodnas). COVID-19 tõi muutuse teatud pärimuskommetesse. Nakkuse leviku tõkestamise meetmed, näiteks eraldatus või vajadus hoida sotsiaalset distantsi, karantiin, mõjutavad negatiivselt traditsioonide edasikandumist (eriti rangete piirangute korral), sest nende elujõulisus põhineb silmast silma suhtlusel. 


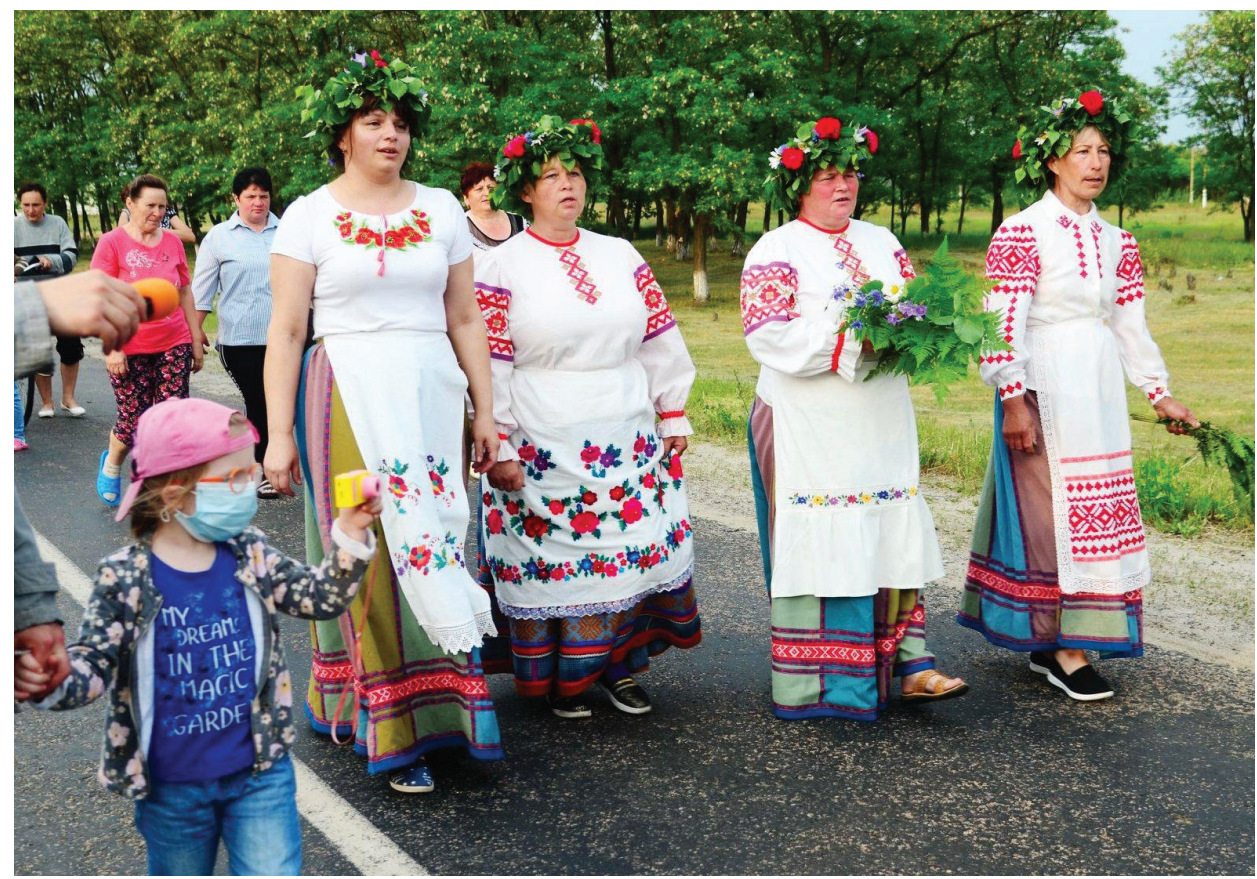

Foto 4. Näkineiu saatmise rituaalil osalejad Vialiki Bori külas. Aliena Paŭloŭskaja foto 2020.

\section{Kokkuvõtteks}

Paljude piirangute ja ohtude põhjuseks saanud pandeemia tingis pöördumise pärimuskultuuri süvakihtide poole, mis tavaelus püsivad latentselt, kuid kriisiolukorras ilmutavad oma antroopset jõudu. Kombetalituste täitmine külades keskendus rituaalide koostisosade olemusele, jättes ajutiselt kõrvale meelelahutusliku visuaalse elemendi. Iseenesest annab nende korraldamise fakt kõikvõimalike piirangute ajal tunnistust pärimusekandjate sügavast sisemisest vajadusest selliste kombetäitmiste järele.

Päevarätiku valmistamise riitus, mille viisid läbi peamiselt pärimusliku loome toetajad kõigi reeglite kohaselt, näitas, et passiivses mälus on alles ennekõike arusaam vajadusest seista ohule vastu kollektiivina. Vastupanu väljendamiseks valitud päevarätiku valmistamine viis ellu idee saada kriisist jagu täiesti uue ja puhta asja loomisega ning selle esemega linna piiramine tugevdas sümboolselt linna kaitsepiire. Vanade kombetalituste uuendamine pandeemia esimese laine kõrgajal Valgevenes omandas uue kaitsva tähenduse. 
Rituaali läbiviimine noorte linlaste poolt sai võimalikuks nende suure huvi tõttu rahvakultuuri vastu ja tänu omandatud teadmistele, kuid protsessi emotsionaalne komponent vastas täielikult arhailistele mustritele ja andis tõendust ohu ületamise arhailiste vormide aktualiseerumisest kriitilistes oludes.

Omapäraseks hirmust ja ebastabiilsusest jagusaamise vahendiks on ka uued naerul põhinevad folkloorivormid, mis pole ohu korral sugugi vähem arhailine reaktsioon.

\section{Tõlkinud Asta Niinemets}

\section{Lühendid}

FATV - Tatsiana Valodzina folkloristlik audiokogu

\section{Kommentaarid}

1 https://isans.org/articles-en/consequences-of-the-coronavirus-epidemic-and-the-belarusian-authorities-strategy-of-denial.html - vaadatud 14.01.2021.

2 Andrej Khadanovichi isiklik lehekülg (https://www.facebook.com/andrej.khadanovich/ posts/10224474735044485 - vaadatud 15.01.2021).

3 Ametlik teave esimese haigestunu kohta ilmus riigis 28. veebruaril 2020, sellest tuleneb ka eriline suhtumine sellesse päeva. (Tõlkijalt: tähele tasub panna ka sõnamängulist elementi - vn kartinka ee pildike; vn karantin ee karantiin.)

${ }^{4}$ Sotsiaalmeedias Pinteresti leheküljele Valgevene kohta postitatud meemid (https:// www.pinterest.co.kr/pin/490048003207444679/, vaadatud 15.01.2021).

5 Twitteri säuts (https://twitter.com/minskrb/status/1233338257678774273?ref_src= twsrc\%5Etfw\%7Ctwcamp\%5Etweetembed\%7Ctwterm\%5E1233338257678774273 $\% 7 \mathrm{Ctwgr} \% 5$ Eshare_1\&ref_url=https\%3A\%2F\%2F42.tut.by\%2F674451 - vaadatud 03.10.2020).

6 "Näkineiu ärasaatmine" on levinud Valgevene kirdeosas, kombetalitus viiakse läbi näkinädala lõpus (järgmine nädalavahetus pärast nelipühi). Tänini on säilinud külast üheaegselt taimestiku ja surnute maailmaga seotud vaimu väljasaatmise semantika. Rituaaliga loodetakse hoida ära põuda ja õnnetusi. 


\section{Kirjandus}

Assman, Yan 2004. Kul'turnaia pamiat': Pis'mo i pamiat' o proshlom i politicheskaia identichnost' v vysokikh kul'turakh drevnosti. Moskva: Iazyki slavianskoi kul'tury.

Baiburin, Al'bert 1993. Ritual v traditsionnoi kul'ture: strukturno-semanticheskii analiz vostochno-slavianskikh obriadov. St. Petersburg: Nauka.

Burton, Ian \& Kates, Robert W. \& White, Gilbert F. 1993. The Environment as Hazard. New York-London: Guilford Press.

Filipčyk, Dzianis 2014. Papshytskaia nametka. Glybotski abydzenny abrad. Belaruski fal'klor. Materyialy i dasledavanni 1, lk 378-386.

Kępiński, Antoni 1977. Lęk. Warszawa: Państwowy Zakład Wydawnictw Lekarskich.

Kutnik, Jan 2017. Wielowymiarowość egzystencjalnego lęku - filozofia egzystencjalna jako inspiracja. Bodzioch-Bryła, Bogusława \& Dorak-Wojakowska, Lilianna (toim). Anatomia strachu. Strach, lęk i ich oblicza we wspótczesnej kulturze. Kraków: Wydawnictwo naukowe Akademii Ignatianum w Krakowie, lk 101-115.

Labačeŭskaja, Volha 2011. Rytual'nyia tkaniny. Abydzenny rytual na Minshchyne. Varfalamiejevaj, Tamara (toim). Tradytsyinaia mastatskaia kul'tura belarusay̆. Tsentral'naia Belarus' 5 (2). Minsk: Vysheishaia shkola, lk 873-896.

Lobachevskaya, Olga 2010. Ritual v povsednevnosti voiny (ob arkhaicheskoi ritual'noi praktike v gody Vtoroi mirovoi voiny v Belarusi). Smalenchuk, Ales (toim). Homohistoricus 2010. Hadavik antrapalahičnaj historyi. Vilnius: EHU, lk 43-53.

Strahhov 2018 = Strakhov, Aleksandr 2018. “Obydennyi” obriad $i$ "obydennyi" produkt na evropeiskom obriadovom fone. Palaeoslavica XXVI, lk 1-279.

Tuchman, Barbara W. 1993. Odlegte zwierciadto czyli rozlicznymi plagami nękane XIV stulecie. Katowice: Wydawnictwo Książnica.

Vovelle, Michel 2004. Śmierć w cywilizacji Zachodu: od roku 1300 po wspótczesność. Gdańsk: Słowo/Obraz Terytoria. 


\section{Summary \\ COVID-19-conditioned folkloristic reactions in Belorussia}

\section{Tatsiana Valodzina}

$\mathrm{PhD}$, Head of the Department of Folklore and Slavic Cultures

the Center for the Belarusian Culture, Language and Literature Researches

of the National Academy of Sciences of Belarus

tanja_volodina@tut.by

\section{Tatsiana Marmysh}

MA in Cultural Studies, Researcher at the Department of Folklore and Slavic Cultures the Center for the Belarusian Culture, Language and Literature Researches

of the National Academy of Sciences of Belarus

ta-m@tut.by

Keywords: archaic, crisis situation, laugh, ritual, pandemic

The article gives an overview of the folk culture mechanisms that helped to cope with the pandemic situation in Belorussia during the first wave of COVID-19 (until midsummer 2020). The article is based on the qualitative analysis of interview texts related to the pandemic as well as the content of internet users' visual reactions (memes, poems, proverbs).

In folk culture the mechanisms helping to overcome the crisis situation often have a ritual-magical nature. When describing the influence of the pandemic on some practices, the authors conclude that their performing in the crisis situation was especially important for the community.

One of the ancient rituals activated for preventing the epidemic was the creation of a magic circle around the village by conducting a procession around the village with a ritual towel ('rushnik-abydzionnik'), which had to be made within one day. On March 28, this one-day-ritual was performed in Minsk with the greatest possible adherence to tradition. The initiators and participants of the practice were mainly representatives of the Students Ethnographic Society. Not all women present knew how to spin or weave, but some of the simplest operations were mastered. The towel was carried around Minsk and brought to a stone on the site of a pagan temple in the centre of Minsk at the sunset. The towel was tied around the stone, and the latter was also covered with threads spun on the same day. The ritual relieved the tension of the participants and fostered awareness of their solidarity, strengthening collective networks, and the feeling of empathy and unity.

COVID-19 also affected the living traditions in Belarus. Some traditional practices were cancelled or postponed. The spread of the pandemic created a negative backdrop for living traditions. However, a number of rites and ceremonies were carried out despite the pandemic in accordance with their spatial and temporal reference. Due to the difficult epidemiological situation, the usual order of ceremonies was changed - their 
duration was reduced without changing the traditional rite structure. Only local residents participated in the rituals; although, formerly, many journalists and tourists had come to the villages from different parts of the country on the days of the ceremonies.

For tradition bearers, such practices during a pandemic are a way to relieve stress and to share problems with people with similar interests. Traditions are one of the constants of their life; maintaining them in times of crises stabilizes the community.

The coronavirus pandemic has caused a powerful explosion of folk art. The texts of various genres, both oral and written (graphic), are rapidly spreading on the Internet. A large number of them are based on the traditional worldview of Belarusians and are expressed in traditional forms (alterations, ditties, anecdotes, anti-sayings, paroemias, etc.). The role of humour has grown tremendously. Jokes and laughter in the face of an external threat are a compensatory mechanism that helps to overcome fear and uncertainty, and common laughter unites and helps to learn new rules of behaviour. Humour is not concerned with the threat of getting ill, but rather individual hygiene practices, the situation of quarantine, and circumstances of the new reality. Thus, humorous folklore becomes a way to adapt to new norms and to overcome fear and instability.

Tatsiana Valodzina $(\mathrm{PhD})$ on valgevene folklorist, folkloristika ja slaavi rahvaste kultuuri sektori juhataja Valgevene Teaduste Akadeemia Valgevene Keele, Kultuuri ja Kirjanduse Instituudis. Ta on ajakirja Belaruski fal'klor asutaja ja peatoimetaja. Tema peamised uurimissuunad on rahvameditsiin, loitsud, kalendrikombestiku sümboolika ja semantika, sakraalsed maastikud, fraseoloogia ja folkloori lühivormid, lastefolkloor. Ta on kümne raamatu autor või kaasautor, avaldanud üle 200 teadusartikli. Ta on ka Valgevene-Eesti koostööväljaannete kaaskoostaja (2018, 2020).

Tatsiana Valodzina (PhD) is Belarusian folklorist, head of the Department of Folk-loristics and Culture of Slavic Peoples at the Institute of Belarusian Language, Culture, and Literature. She is the founder and editor-in-chief of the journal Belaruski fal'klor (Belarusian Folklore). Her main research areas cover folk medicine, charms, symbols and semantics of calendar rituals, sacral landscapes, phraseology and short forms of folklore, and children's folklore. She has authored or co-authored ten books and published more than 200 scientific articles, and is also co-compiler of Belarusian-Estonian co-publications (2018, 2020).

tanja_volodina@tut.by

Tatsiana Marmysh (MA) on Valgevene Teaduste Akadeemia Valgevene Kultuuri, Keele ja Kirjanduse Instituudi slaavi rahvaste folkloristika ja kultuuri osakonna teadur. Tema uurimisvaldkonda kuuluvad nüüdisfolkloor, mittemateriaalne kultuuripärand ja selle kaitse. 
Tatsiana Marmysh, MA in Cultural Studies, is Research Fellow at the Department of Folklore and Slavic Cultures at the Center for the Belarusian Culture, Language and Literature Researches of the National Academy of Sciences of Belarus. Her field of interests covers modern folklore, intangible cultural heritage and its protection.

ta-m@tut.by 